\title{
The challenges of measuring Methane from space with a lidar
}

\author{
H. Riris*a ${ }^{*}$ K. Numata ${ }^{\mathrm{a}}$, S. Wu ${ }^{\mathrm{a}}$, M. Fahey ${ }^{\mathrm{a}}$, B. Gonzalez ${ }^{\mathrm{a}}$, X. Sun ${ }^{\mathrm{a}}$, J. Mao ${ }^{\mathrm{b}}$, M. Rodriguez $^{\mathrm{c}}$, \\ ${ }^{\mathrm{a}}$ Goddard Space Flight Center, Greenbelt, MD, USA 20771; ${ }^{\mathrm{b} U n i v e r s i t y ~ o f ~ M a r y l a n d, ~ C o l l e g e ~ P a r k, ~}$ \\ MD, USA 200742, 'Sigma Space, Laurel, MD, USA, 20706
}

\begin{abstract}
The global and regional quantification of methane fluxes and identification of its sources and sinks has been highlighted as one of the goals of the NASA 2017 Earth Science Decadal Survey. Detecting methane from space and airborne platforms with an active (laser) remote sensing instrument presents several unique technology and measurement challenges. The instrument must have a single frequency, narrow-linewidth light source, and photon-sensitive detector at the right spectral region to make continuous measurements from orbit, day and night, all seasons and at all latitudes. It must have a high signal to noise ratio and must be relatively immune to biases from aerosol/cloud scattering, spectroscopic and meteorological data uncertainties, and instrument systematic errors.

At Goddard Space Flight Center (GSFC), in collaboration with industry, we have developed an airborne instrument to measure methane. Our instrument is a nadir-viewing lidar that uses Integrated Path Differential Absorption (IPDA), to measure methane near $1.65 \mu \mathrm{m}$. We sample the absorption line using multiple wavelengths from a narrow linewidth laser source and a sensitive photodetector. This measurement approach provides maximum information content about the $\mathrm{CH} 4$ column, and minimizes biases in the XCH4 retrieval.

In this paper, we will review our progress to date and discuss the technology challenges, options and tradeoffs to measure methane from space and airborne platforms.
\end{abstract}

Keywords: lidar, spectroscopy, methane, airborne instruments

\section{INTRODUCTION}

Methane (CH4) is the second most important anthropogenic greenhouse gas (GHG) with a higher radiative forcing potential than Carbon Dioxide (CO2) on a per molecule basis ${ }^{1}$, making anthropogenic $\mathrm{CH} 4$ a critical target for mitigation. The current $\mathrm{CH} 4$ global mixing ratio is 1852 parts per billion (ppb) ${ }^{2,3}$. Anthropogenic CH4 is responsible for a significant portion of the global warming produced by all well-mixed greenhouse gases and contributes to the formation of ozone ${ }^{4}$, another GHG and air pollutant.

The existing CH4 observing network has proven inadequate to constrain global, regional, and sectoral sources, and explain observed trends and variation in atmospheric CH4 over the last few decades. Therefore, there is a critical need for CH4 observations for constraining the strength and distribution of methane's sources, including natural (e.g., wetlands) and anthropogenic (e.g., energy sector) ones. Much of the year-to-year variations in methane's global growth rate are likely from variations in wetland emissions and part of the recent increasing trend in methane's growth rate may be associated with increased energy extraction activities ${ }^{5,6}$. An adequate $\mathrm{CH} 4$ observing network is necessary to monitor the interaction between the carbon cycle and climate change, such as the potential release of $\mathrm{CH} 4$ from stored carbon reservoirs (e.g., Arctic and boreal soils) and changes in natural emissions. The current CH4 observing network does not provide the necessary data to understand and constrain methane's sources, such as from permafrost thaw, wetlands, which challenges our ability to make confident projections of future climate. The importance of measuring $\mathrm{CH} 4$ is also reflected in the recent Earth Science Decadal Survey ${ }^{7}$ and the recent report by the Carbon Climate Workshop ${ }^{8}$.

Our current understanding of $\mathrm{CH} 4$ distributions and processes is founded mostly on precise and accurate ground-based, in-situ measurements from global monitoring networks ${ }^{9,}{ }^{10}$. The location and frequency of these measurements is, however, very sparse on a global scale and is even sparser at high latitudes where the thawing Arctic permafrost is of particular concern. Large quantities of organic carbon are stored in the Arctic permafrost and a warming climate can induce drastic changes in carbon emissions and a subsequent positive feedback mechanism that can significantly accelerate climate change ${ }^{11}$. 
Global measurements from satellites are available from passive optical sensors AIRS ${ }^{12}$, SCIAMACHY ${ }^{13},{ }^{14}$, TES ${ }^{15}$, $\mathrm{IASI}^{16}$, and GOSAT ${ }^{17}$, but currently lack the required sensitivity to derive regional CH4 sources. Passive sensors measuring reflected sunlight are limited to sunlit areas of the planet and their sensitivity falls off at low sun angles, increasing cloud cover, aerosol scattering, and low surface reflectivity. Recent observations indicate that the thawing Arctic permafrost is active even during the cold season18 highlighting the need for continuous sampling at high latitudes even in the winter months.

These measurements need to be able to resolve $\mathrm{CH} 4$ concentration uncertainties over global and regional scales, at all latitudes throughout the year to address important science issues, such as how the large terrestrial carbon reservoir will respond in a warming world (e.g., permafrost thaw), the need to constrain large emission variations from tropical wetlands, and the impact of energy extraction activities on methane's recent global growth.

Active (laser) remote sensing technology will be a key step in obtaining $\mathrm{CH} 4$ measurements to supplement existing observations from passive satellite instruments and the sparse surface monitoring network. Active measurements will enable accurate CH4 observations at high latitudes, during all seasons and at night, over land and water surfaces, and in the presence of scattered or optically thin clouds and aerosols, and with higher coverage than passive instruments. Together, data from an observational suite of active, passive and in situ instruments will provide sufficient coverage, sampling, and precision to constrain emissions on global and regional scales and potentially some sectoral CH4 emission sources (e.g., oil and natural gas exploration in the central U.S.).

The only active trace gas mission currently in development is the Franco-German MEthane Remote sensing LIdar missioN (MERLIN) by the French Centre National d'Etudes Spatiales (CNES) in collaboration with the German Aerospace Centre (DLR) scheduled for launch in 2021 ${ }^{19}$, 20 The MERLIN mission targets an 8-36 ppbv relative random error in the methane column abundance with a $50 \mathrm{~km}$ horizontal resolution.

At NASA Goddard Space Flight Center (GSFC), we have also been developing an active, airborne lidar to measure atmospheric methane using Integrated Path Differential Absorption (IPDA) as a precursor to a space mission to measure CH4 from orbit.

\section{GSFC MEASUREMENT APPROACH}

An IPDA lidar measures the absorption of laser pulses by a trace gas when tuned to a wavelength coincident with an absorption line ${ }^{21-31}$. Using the instrument in a sounding (surface reflection) mode which enables integrated column trace gas measurements from orbit with relatively modest laser power. Although in principle, only two wavelengths ("on” and "off" the absorption line) are needed to determine the transmittance through the atmospheric column, our technique uses multiple wavelengths to probe the absorption feature.

CH4 has absorption lines in the near infrared spectral region at 3.3, 2.4 and $1.65 \mu \mathrm{m}$. The lines at $1.65 \mu \mathrm{m}$ are best suited for active remote sensing from space because they have the right linestrengths and there is very little interference from other molecules. Unfortunately, there are no commercially available lasers in this spectral region.

There are two primary candidate lines can be used for CH4 monitoring: One at $1650.96 \mathrm{~nm}$ and one at $1645.55 \mathrm{~nm}$. The GSFC IPDA lidar uses a tunable, narrow-linewidth light source and a photon-sensitive detector coincident with the CH4 absorption at $1650.96 \mathrm{~nm}$. The CH4 line is mostly isolated from adjacent CO2 lines and there is very little water (H2O) vapor interference. The MELRIN line at $1645.55 \mathrm{~nm}$ is not as well less suited to our technique because it is interfered with by $\mathrm{H} 2 \mathrm{O}$ vapor at $\sim 1645.47 \mathrm{~nm}$ and it is wider than our line ( $56 \mathrm{pm}$ vs. $\sim 36 \mathrm{pm})$, an important consideration because it increases the tuning requirement for our laser transmitter. Fig. 1 shows the two-way atmospheric transmittance spectrum for the two lines from a $400 \mathrm{~km}$ orbit using the 2008 HITRAN database ${ }^{32}$ and a US standard atmosphere.

The GSFC lidar (Figure 2) uses multiple wavelengths to probe the CH4 absorption feature. Our IPDA approach has been validated experimentally over several years in multiple airborne campaigns and extensive ground tests with our CO2, O2, and CH4 IPDA lidars. Using multiple wavelengths can reduce errors that may affect the measurement precision ${ }^{33}$, measure the spectral shift of the line with changing atmospheric pressure ${ }^{34}$, generate atmospheric backscatter profiles of the entire column ${ }^{35}$, and enable retrievals of trace gas mixing ratios above and below the planetary boundary layer ${ }^{36}$. 

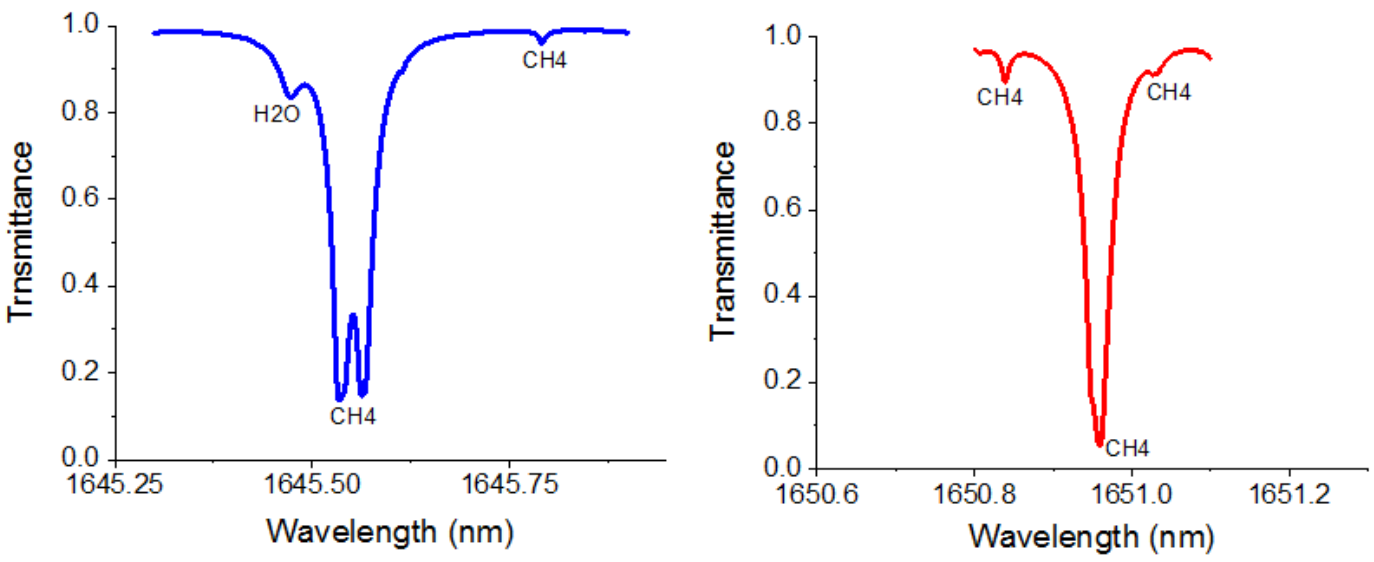

Figure 1 Atmospheric transmittance at $1645.5 \mathrm{~nm}$ (left) and $1650.9 \mathrm{~nm}$ (right) wavelengths using a US Standard Atmosphere and the HITRAN 2008 database.
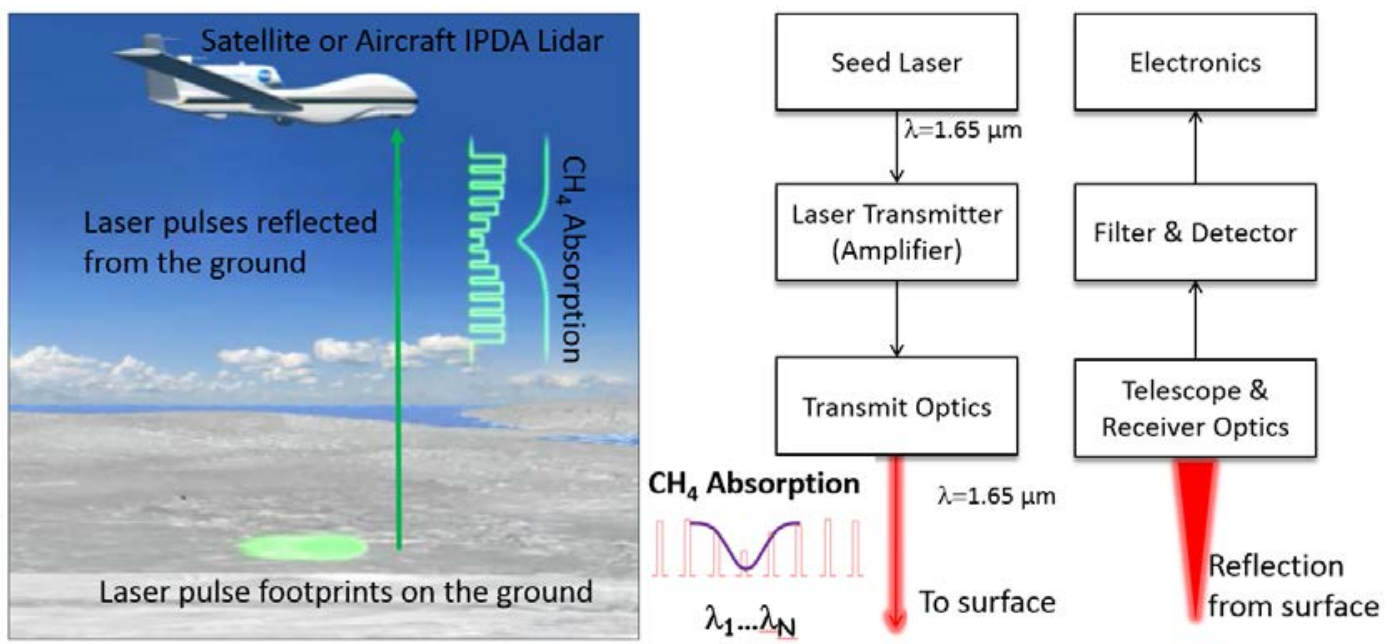

Figure 2. (Left) An Integrated Path Differential Absorption (IPDA) lidar measures the absorption of laser pulses by a trace gas at multiple wavelengths. (Right) Simplified functional block diagram of the CH4 IPDA lidar.

In late 2015, we flew the CH4 lidar instrument on NASA's DC-8 airborne laboratory. The airborne IPDA lidar used two different laser transmitters. The first was an Optical Parametric Amplifier (OPA) ${ }^{37,38}$ and the second was an Optical Parametric Oscillator $(\mathrm{OPO})^{39}$. Only one laser transmitter was used at a time by using a movable mirror to select the desired transmitter.

The OPA, used 20 wavelengths, but was simpler to implement than the OPO, because it did not require an optical resonator cavity, was easier to align and tune, and used only two seed lasers. The OPO used 5 wavelengths and required a separate seed laser for each wavelength. Table 1 summarizes the major parameters of the 2015 airborne IPDA lidar and Figure 3 shows the instrument in the DC-8 prior to flight. Both the OPO and OPA used a master seed laser locked on the CH4 absorption peak at $1650.96 \mathrm{~nm}$. The locking technique is the same for both the OPA and OPO, and is described by Numata ${ }^{40}$. It is based on the technique used by Pound-Drever-Hall ${ }^{41}$ and is similar to the technique used by $\mathrm{Fix}^{42}$. The detector is an e-APD that has flown in multiple airborne missions ${ }^{43-45}$.

Our retrieval algorithm used a least squares fit to minimize the root mean squared error between the IPDA lidar measurements and the model prediction and is similar to the approach used by Abshire et.al. ${ }^{46}$ in their CO2 retrievals. The remaining design details of our instrument and results of our airborne demonstration were summarized in a recent publication. ${ }^{47}$ 
Table 12015 CH4 Airborne Lidar

\begin{tabular}{lll}
\hline Parameter & OPA & OPO \\
\hline Center Wavelength & $1650.958 \mathrm{~nm}$ & $1650.958 \mathrm{~nm}$ \\
Number of wavelengths used & 20 & 5 \\
Transmitter Energy/pulse & $\sim 25-30 \mu \mathrm{J}$ & $\sim 250 \mu \mathrm{J}$ \\
Transmitter Pulse rate & $10 \mathrm{kHz}$ & $5 \mathrm{kHz}$ \\
Transmitter divergence & $\sim 150 \mu \mathrm{rad}$ & $\sim 150 \mu \mathrm{rad}$ \\
Spectral Linewidth & $\sim 500 \mathrm{MHz}$ & $<300 \mathrm{MHz}^{*}$ \\
Number of seed lasers used & 2 & 5 \\
Pump laser & Burst mode Yb Fiber & Single pulse Nd:YAG \\
Pump laser energy & $350 \mu \mathrm{J}$ & $1.2 \mathrm{~mJ}$ \\
Receiver diameter & $20 \mathrm{~cm}$ & $20 \mathrm{~cm}$ \\
Receiver Field of view & $300 \mu \mathrm{rad}$ & $300 \mu \mathrm{rad}$ \\
Receiver band pass & $0.8 \mathrm{~nm}(\mathrm{FWHM})$ & $0.8 \mathrm{~nm}(\mathrm{FWHM})$ \\
Detector & $4 \mathrm{x} 4 \mathrm{HgCdTe}$ e-ADP & $4 \times 4 \mathrm{HgCdTe}$ e-ADP \\
Detector Pixel Pitch & $80 \mu \mathrm{m}$ & $80 \mu \mathrm{m}$ \\
Detector QE & $\sim 90 \%$ & $\sim 90 \%$ \\
Detector Temperature & $80 \mathrm{~K}$ & $80 \mathrm{~K}$ \\
Detector bandwidth & $7 \mathrm{MHz}$ & $7 \mathrm{MHz}$ \\
Averaging time & $1 / 16 \mathrm{sec}$ & $1 / 16 \mathrm{sec}$ \\
\hline
\end{tabular}

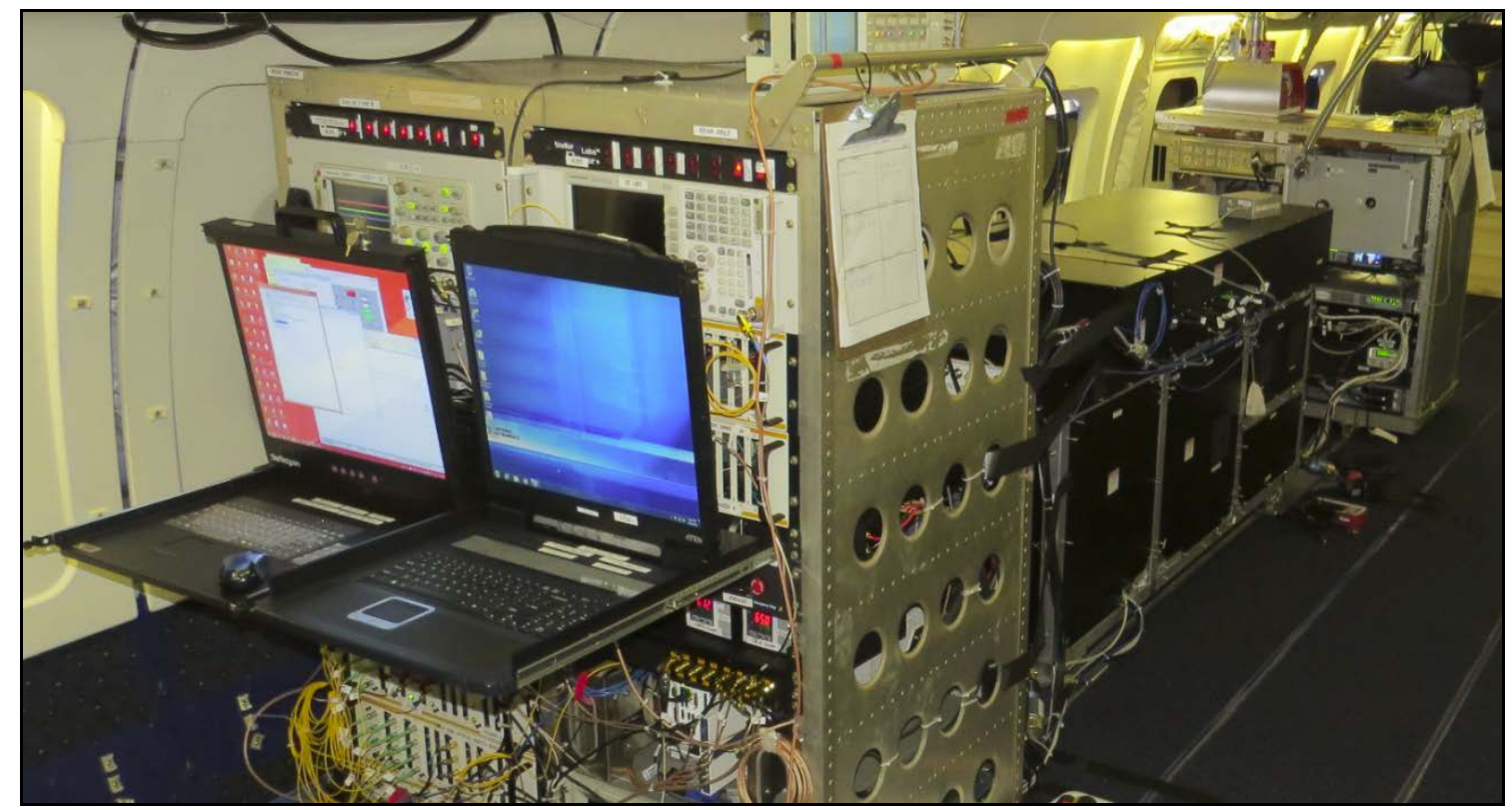

Figure 3 The 2015 GSFC CH4 IPDA Lidar in the DC-8 prior to flight.

\section{LASER TECHNOLOGY}

Most of the key technologies for a space CH4 lidar have a long heritage, and most have been demonstrated in previous space missions. Telescopes of various sizes (1.0 and $0.7 \mathrm{~m}$ diameter) for lidar missions have flown on the Ice, Cloud, and land Elevation Satellite (ICESat-I and soon ICESat-II), Cloud-Aerosol Lidar and Infrared Pathfinder Satellite Observation (Calipso), and Cloud-Aerosol Transport System (CATS). The command \& control and data acquisition 
electronics will be similar to other lidar missions. The only remaining low technology readiness level component of the instrument is the laser transmitter.

The laser transmitter must have high energy, narrow linewidth and must be rapidly tunable over the absorption line. Depending on the receiver size and other instrument parameters we calculate that approximately $600 \mu \mathrm{J}$ is needed to obtain a measurement with a $0.5 \%$ precision from space.

The primary means to generate $1.65-\mu m$ laser radiation has been to use non-linear optical parametric techniques: optical parametric amplifiers (OPA) or oscillators (OPO) ${ }^{48}$. MERLIN uses a two-wavelength OPO. Our airborne OPA, which used 20 wavelengths, produced better fits, was simpler to implement than the OPO because it did not require an optical resonator cavity, and was easier to align and tune. However, it is extremely difficult to scale the OPA energy to that needed for space ( $600 \mu \mathrm{J}$ depending on the receiver size and other instrument parameters) and maintain a narrow linewidth. The highest energy we obtained in the laboratory with our OPA was $290 \mu \mathrm{J}$ using a two-stage OPA, and the burst-mode $\mathrm{Yb}$ fiber laser amplified by a custom solid-state amplifier as a pump. However, at high energies, the OPA output spectrum typically consists of sharp peak near the seed wavelength and a broad side lobe, when the parametric gain is high. In that case, we cannot clearly define the linewidth but it is generally too wide for accurate CH4 IPDA lidar measurements. In addition, for a space mission we are aiming for a simple and efficient single stage - not a complex multi-stage - OPA based on quasi-phase matching (QPM). In this configuration, we have observed that the OPA output linewidth does not fully converge to the seed linewidth, giving wide side lobes, especially when pump and seed fluences are high and low, respectively ${ }^{49}$. Back-conversion and parametric amplification of the seed's side lobes are possible causes. If the seed laser power can be significantly scaled up then it may be possible to achieve energies of $600 \mu \mathrm{J}$ out of the OPA with a narrow linewidth. With the existing seed and pump laser technology, we do not see a path to space for the OPA in the near future. However, it remains a viable transmitter for CH4 measurements from an airborne platform.

In the OPO, narrow linewidth was achieved by using an optical resonator cavity, which also enhances the energy of the non-linear conversion. Our 5-wavelength OPO used a $1.2 \mathrm{~mJ}$ GSFC-built solid-state pump laser and a triangular optical ring cavity. We have since replaced the GSFC-built solid-state pump laser with a smaller, compact Yb fiber laser and redesigned the OPO cavity to improve stability (Figure 4).

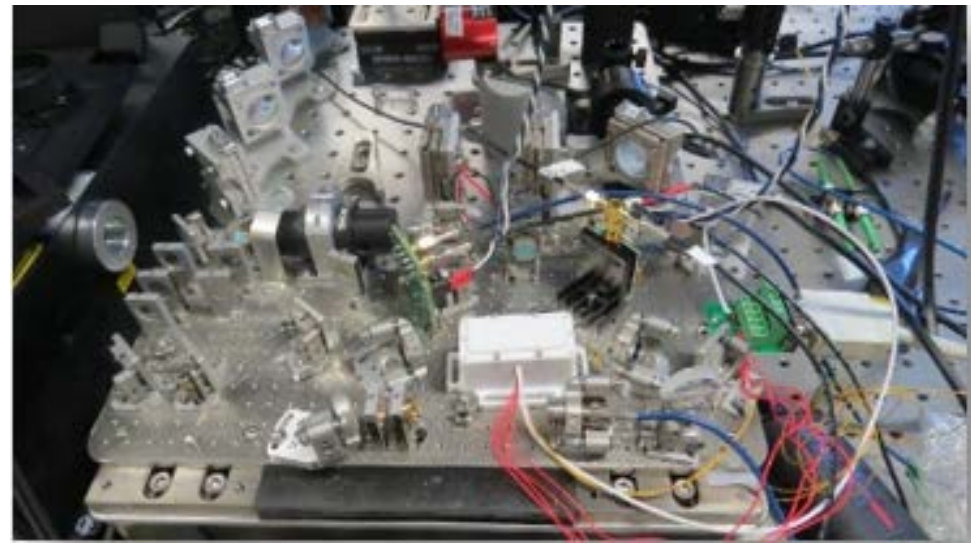

Figure 4 Our airborne 5-wavelength OPO used a $1.2 \mathrm{~mJ}$ GSFC-built solid-state pump laser and a triangular optical ring cavity. We have since replaced the GSFC-built solid-state pump laser with a smaller, compact Yb fiber laser and used a single DBR seed laser that step-tunes over the CH4 absorption line.

We also replaced the five seed diode lasers with a single custom-made DBR laser that is stepped tuned over the absorption line. We now use sixteen wavelengths to tune over the CH4 absorption line. That simplified the OPO design considerably. In the laboratory we demonstrated energies of $\sim 250 \mu \mathrm{J}$ at $5 \mathrm{kHz}$ with a narrow (transform limited) linewidth. The multi-wavelength OPO energy could be scaled to space and remains our baseline approach. However, it still requires optical phase-lock loop and cavity control.

In recent years, resonantly pumped Erbium (Er) doped YAG, Er:YAG and Er:YGG, lasers, which directly emit at 1645.5 and $1650.96 \mathrm{~nm}$, respectively offer another option for a CH4 transmitter. Using Er:YAG for CH4 detection dates back to 
$1972^{50}$. In recent years, successful demonstrations and commercialization of high power and high spectral brightness pump sources at $1470 \mathrm{~nm}$ and $1532 \mathrm{~nm}$, driven in large part by the various industries including defense, telecommunications and medical, have afforded the realization of resonant pumping of of Er:YAG ${ }^{51-54}$ and Er:YGG ${ }^{55,56}$ lasers. The emission cross-section of Er:YAG crystal is centered near $1645.3 \mathrm{~nm}$ and falls off rapidly at $1650.96 \mathrm{~nm}$. It is near the MERLIN lines at $1645.55 \mathrm{~nm}$ which are relatively wide ( $\sim 56 \mathrm{pm})$. Our CH4 line at $1650.96 \mathrm{~nm}$ is narrower ( $36 \mathrm{pm})$ which makes fast tuning easier. Unfortunately, Er:YAG cannot be used as a gain medium at $1650.96 \mathrm{~nm}$ but Er:YGG can be used as a potential medium for lasing at that wavelength. Our preliminary radiative transfer calculations show that both lines (Er:YAG at $1645.55 \mathrm{~nm}$ and Er:YGG at $1650.96 \mathrm{~nm}$ ) have similar temperature sensitivity and are well suited for space born $\mathrm{CH} 4$ measurements. Recent high accuracy spectroscopic measurements indicate that line mixing effects in the Er:YAG $1645.55 \mathrm{~nm}$ line $^{57}$ should also be taken into account. We expect similar effects to be present for the Er:YGG line at $1650.96 \mathrm{~nm}$.

Both materials are good candidates for a space CH4 laser transmitter but Er:YAG is more readily available. Power scaling for both materials, and most importantly multi-wavelength operation and tuning considerations remain. For both materials, the gain peak is slightly off the $\mathrm{CH} 4$ absorptions lines requiring the use of a tuning element, such as an etalon, in the cavity. However, for a multi-wavelength IPDA that introduces yet another element that needs to be tuned and controlled at high precision.

\section{SUMMARY}

Anthropogenic $\mathrm{CH} 4$ is responsible for a significant portion of the global warming produced by all well-mixed greenhouse gases. Despite the critical importance of $\mathrm{CH} 4$ for climate, the existing $\mathrm{CH} 4$ observing network has proven inadequate to constrain global, regional, and sectoral sources, and explain observed trends and variation in atmospheric $\mathrm{CH} 4$ over the last few decades. Part of the increasing trend in methane's growth rate over the last decade may be associated with anthropogenic sources, including increased energy extraction activities. Identifying methane "super emitters" and quantifying regional-scale emissions from specific industry sectors (e.g., domestic natural gas production and storage) which are projected to increase significantly in the next few decades will require substantial investments in CH4 monitoring technology. At GSFC, we developed a multi-wavelength IPDA lidar and demonstrated CH4 column measurements using an optical parametric oscillator (OPO) and optical parametric amplifier (OPA) laser transmitter and sensitive avalanche photodiode detector. The lidar measured the atmospheric $\mathrm{CH} 4$ absorption at multiple, discrete wavelengths near $1650.96 \mathrm{~nm}$. The stability and reliability of the laser transmitters need to improve considerably but the basic measurement approach has been demonstrated. However, many technical challenges remain to scale the space.

Generally, an OPA is simpler to implement than an OPO because it does not require an optical resonator cavity and is easier to align and tune. However, it is extremely difficult to scale the power of the OPA and maintain a narrow linewidth. After extensive testing we have concluded that it is not feasible to scale the OPA laser energy to the level needed for space without significant improvements considerable investments in the seed and pump laser.

In an OPO, a narrow linewidth is achieved by using an optical resonator cavity, which also enhances the energy of the non-linear conversion. Our new multi-wavelength OPO is scalable to space, but still requires phase-locking loops and cavity tuning. The OPO will remain the baseline option until solid-state approaches (Er:YAG/Er:YGG) can be convincingly demonstrated.

It would seem that the simplest and most promising technology at this wavelength range is Er:YAG/Er:YGG. The lasing occurs near (but unfortunately not exactly) at the CH4 absorptions 1645 and $1651 \mathrm{~nm}$. Power scaling has already been demonstrated with the desired spectral characteristics but without fast tuning and only at one or two wavelengths. The Er:YAG/Er:YGG still require a tuning element in the cavity to lase at the right wavelength. If the tuning problem can be solved this technology may be the most promising.

\section{ACKNOWLEDGEMENTS}

The authors would like to acknowledge the generous support by the Earth Science Technology Office (ESTO) Advanced Component Technology Program (ACT-13) and the GFSC Internal Research and Development (IRAD) Program. The authors would like to recognize Dr. Piers Sellers, who passed away in December 2016, for his unwavering support of our 
lidar development and flight demonstration. The authors would also like to thank Dr. Graham Allan and Dr. James Abshire for valuable discussions and consultations. The authors would also like to express their appreciation to the DC-8 flight operations team at the Science Aircraft Integration Facility in Palmdale, CA.

\section{REFERENCES}

[1] Intergovernmental Panel on Climate Change, IPCC Fifth Assessment Report, Cambridge Univ. Press, Cambridge, U. K. and New York. (2013).

[2] Saunois, Marielle, Philippe Bousquet, Ben Poulter, Anna Peregon, Philippe Ciais, Josep G. Canadell, Edward J. Dlugokencky et al. "The global methane budget 2000-2012." Earth System Science Data 8, no. 2, 697, (2016).

[3] Trends in Atmospheric Methane, https://www.esrl.noaa.gov/gmd/ccgg/trends_ch4/, accessed on May 4 th 2017.

[4] Fiore, A. M., D. J. Jacob, B. D. Field, D. G. Streets, S. D. Fernandes, and C. Jang, "Linking ozone pollution and climate change: The case for controlling methane", Geophys. Res. Lett., 29 (19), 1919, doi:10.1029/2002GL015601, 2002.

[5] Franco, B., E. Mahieu, L. Emmons, Z. Tzompa-Sosa, E. Fischer, K. Sudo, B. Bovy, S. Conway, D. Griffin, J. Hannigan, K. Strong, and K. Walker (2016), "Evaluating ethane and methane emissions associated with the development of oil and natural gas extraction in North America", Environ. Res. Lett., 11.4 (2016).

[6] Turner, A. J., D. J. Jacob, J. Benmergui, S. C. Wofsy, J. D. Maasakkers, A. Butz, O. Hasekamp, and S. C. Biraud (2016), "A large increase in U.S. methane emissions over the past decade inferred from satellite data and surface observations", Geophys. Res. Lett., 43, 2218-2224, (2016). doi:10.1002/2016GL067987.

[7] DECADAL SURVEY FOR EARTH SCIENCE AND APPLICATIONS FROM SPACE, 2017. http://sites.nationalacademies.org/DEPS/esas2017/index.htm (last accessed on 19 ${ }^{\text {th }}$ August 2018).

[8] Schimel, David, et al. "Observing the carbon-climate system." arXiv preprint arXiv:1604.02106 (2016).

[9] Dlugokencky, EJ; Steele, LP, Lang, PM, Masarie, K. A., "Atmospheric Methane at Mauna-Loa and Barrow Observatories - Presentation and Analysis of In-Situ Measurements", J. Geophys. Res., 100, 23103-23113, (1995). DOI: 10.1029/95JD02460.

[10] Prinn, R. G., et al. (2000), "A history of chemically and radiatively important gases in air deduced from ALE/GAGE/AGAGE", J. Geophys. Res., 105 (D14), 17751- 17792, (2000).

[11] Schuur, E.A.G., McGuire, A.D., Schädel, C., Grosse, G., Harden, J.W., Hayes, D.J., Hugelius, G., Koven, C.D., Kuhry, P., Lawrence, D.M. and Natali, S.M., "Climate change and the permafrost carbon feedback". Nature, 520 (7546), pp.171-179, (2015).

[12] Coheur, P.F., Xiong, X., C. D. Barnet, Q. Zhuang, T. Machida, C. Sweeney, and P. K. Patra, "Mid-upper tropospheric methane in the high Northern Hemisphere: Spaceborne observations by AIRS, aircraft measurements, and model simulations", J. Geophys. Res., 115, D19309, (2010). doi:10.1029/2009JD013796

[13] Buchwitz, M., R. De Beek, J. P. Burrows, H. Bovensmann, T. Warneke, J. Notholt, J. F. Meirink, A. P. H. Goede, P. Bergamaschi, S. Körner, M. Heimann, A. Schulz, "Atmospheric methane and carbon dioxide from SCIAMACHY satellite data: initial comparison with chemistry and transport models", Atmos. Chem. Phys., 5, 941-962, (2005).

[14] Bergamaschi, P., Frankenberg, C., Meirink, J.F., Krol, M.C., Dentener, F.J.; Wagner, T., Platt, U., Kaplan, J.O., Körner, S.; Heimann, M.; Dlugokencky, E.J.; Goede, A. De, "Satellite chartography of atmospheric methane from SCIAMACHY on board ENVISAT: 2. Evaluation based on inverse model simulations", Journal of Geophysical Research-Atmospheres, Volume: 112, pp. D02304/1-D02304/26, (2007).

[15] Wecht, K. J., Jacob, D. J., Wofsy, S. C., Kort, E. A., Worden, J. R., Kulawik, S. S., Henze, D. K., Kopacz, M., and Payne, V. H., "Validation of TES methane with HIPPO aircraft observations: implications for inverse modeling of methane sources", Atmos. Chem. Phys., 12, 1823-1832, doi:10.5194/acp-12-1823-2012, (2012).

[16] August, T., Klaes, D., Schlussel, P., Hultberg, T., Crapeau, M., Arriaga, A., O'Carroll, A., Coppens, D., Munro, R., Calbet, X., "IASI onMetop-A: Operational Level 2 retrievals after five years in orbit", Journal of Quantitative Spectroscopy \& Radiative Transfer 113, 1340-1371, (2012).

[17] Yokota, T., Y. Yoshida, N. Eguchi, Y. Ota, T. Tanaka, H. Watanabe, and S. Maksyutov, "Global Concentrations of CO2 and CH4 Retrieved from GOSAT: First Preliminary Results", SOLA, Vol. 5, 160?163, (2009). doi:10.2151/sola.2009?041 
[18]Zona, Donatella, Beniamino Gioli, Róisín Commane, Jakob Lindaas, Steven C. Wofsy, Charles E. Miller, Steven J. Dinardo et al. "Cold season emissions dominate the Arctic tundra methane budget." Proceedings of the National Academy of Sciences 113, no. 1, 40-45, (2016).

[19] Stephan, C., M. Alpers; B. Millet; G. Ehret; P. Flamant; C. Deniel, "MERLIN: a space-based methane monitor", "Lidar Remote Sensing for Environmental Monitoring XII. Proceedings of the SPIE, Volume 8159, pp. 815908815908-15, (2011).

[20]Kiemle, M. Quatrevalet, G. Ehret, A. Amediek, A. Fix, and M. Wirth, "Sensitivity studies for a space-based methane lidar mission", Atmos. Meas. Tech. Discuss., 4, 3545-3592, 2011.

[21] Measures, R., Laser Remote Sensing, Chapter 7, John Wiley \& Sons, New York, 1984

[22] Abshire, J.B., H. Riris, C. Weaver, J. Mao, G. Allan, W. Hasselbrack, and E. Browell, "Airborne measurements of $\mathrm{CO} 2$ column absorption and range using a pulsed direct-detection integrated path differential absorption lidar," Appl. Opt. 52, 4446-4461 (2013).

[23] Ehret, G., Kiemel, C., Wirth W., Amediek, A., et.al, "Space-borne remote sensing of CO2, CH4, and N2O by integrated path differential absorption lidar: a sensitivity analysis", Appl. Phys. B 90, 593-608, (2008).

[24]A. Amediek, Fix, A., Wirth, M., Ehret, G., "Development of an OPO system at 1.57 ?m for integrated path DIAL measurement of atmospheric carbon dioxide", Appl. Phys. B 92, 295-302, DOI: 10.1007/s00340-0083075-6, (2008).

[25] Riris, H., K. Numata, S. Li, S. Wu, A. Ramanathan, M. Dawsey, J. Mao, R. Kawa, and J. Abshire, "Airborne measurements of atmospheric methane column abundance using a pulsed integrated-path differential absorption lidar," Appl. Opt. 51, 8296-8305 (2012).

[26] Riris, H., M. Rodriguez, G.R. Allan, W. Hasselbrack, J. Mao, M. Stephen, J. Abshire, "Pulsed airborne lidar measurements of atmospheric optical depth using the Oxygen A-band at $765 \mathrm{~nm}$," Applied Optics, 52(25), 6369-6382 (2013).

[27] Spiers, Gary D., et al. "Atmospheric CO 2 measurements with a 2 ?m airborne laser absorption spectrometer employing coherent detection." Applied Optics 50.14, 2098-2111, (2011).

[28] Dobler, Jeremy T., et al. "Atmospheric CO2 column measurements with an airborne intensity-modulated continuous wave 1.57 ?m fiber laser lidar." Applied Optics 52.12, 2874-2892, (2013).

[29] Amediek, A., G. Ehret, A. Fix, M. Wirth, C. Büdenbender, M. Quatrevalet, C. Kiemle, and C. Gerbig, "CHARM-F-a new airborne integrated-path differential-absorption lidar for carbon dioxide and methane observations: measurement performance and quantification of strong point source emissions," Appl. Opt. 56, 5182-5197 (2017).

[30] Fix, Andreas, Axel Amediek, Christian Büdenbender, Gerhard Ehret, Mathieu Quatrevalet, Martin Wirth, Jens Löhring et al., "Development and first results of a new near-ir airborne greenhouse gas lidar", Optics and Photonics for Energy and the Environment, pp. EM3A-3, Optical Society of America, (2015).

[31] Amediek, Axel, Gerhard Ehret, Andreas Fix, Martin Wirth, M. Quatrevalet, C. Büdenbender, C. Kiemle, J. Loehring, and C. Gerbig. "First airborne IPDA lidar measurements of methane and carbon dioxide applying the DLR greenhouse gas sounder CHARM-F", AGU Fall Meeting Abstracts, (2015).

[32] Rothman, L. S., et al. "The HITRAN 2008 molecular spectroscopic database." Journal of Quantitative Spectroscopy and Radiative Transfer, 110, 9, 533-572, (2009).

[33] Chen, Jeffrey R., Kenji Numata, and Stewart T. Wu. "Error reduction in retrievals of atmospheric species from symmetrically measured lidar sounding absorption spectra." Optics express 22.21, 26055-26075, (2014).

[34] Ramanathan, A., Jianping Mao, Graham R. Allan, Haris Riris, Clark J. Weaver, William E. Hasselbrack, Edward V. Browell, James B. Abshire, "Spectroscopic measurements of a CO2 absorption line in an open vertical path using an airborne lidar," Applied Physics Letters, 103, 214102 (2013), DOI:http://dx.doi.org/10.1063/1.4832616

[35] Allan, G. R., H. Riris, W. Hasselbrack, M. Rodriguez, A. Ramanathan, X. Sun, J. Mao, and J. B. Abshire. "Atmospheric Backscatter Profiles at 765nm and 1572nm from Pulsed Lidar Measurements of CO2 and O2 Column Absorption from the 2013 ASCENDS Flight Campaign." AGU Fall Meeting Abstracts, vol. 1, p. 0211, (2013).

[36] Ramanathan, Anand K., Jianping Mao, James B. Abshire, and Graham R. Allan. "Remote sensing measurements of the CO2 mixing ratio in the planetary boundary layer using cloud slicing with airborne lidar." Geophysical Research Letters 42, no. 6, 2055-2062, (2015).

[37] Numata, K., Riris, H., S. Li, S. Wu, S. R. Kawa, M. Krainak, J. Abshire, "Ground demonstration of trace gas lidar based on optical parametric amplifier", Journal of Applied Remote Sensing, Vol. 6, 063561-1, (2012). 
[38]Engin, Doruk, Ibraheem Darab, John Burton, Jean-Luc Fouron, Frank Kimpel, Brian Mathason, Shantanu Gupta, and Mark Storm. "Highly-efficient, high-energy pulse-burst Yb-doped fiber laser with transform limited linewidth." In SPIE Defense+ Security, pp. 908112-908112. International Society for Optics and Photonics, (2014).

[39] Numata, K., Riris, H., Wu, S., "Fast-switching methane lidar transmitter based on a seeded optical parametric oscillator", Applied Physics B, 116, 4, 959-966, (2014).

[40] Numata, Kenji, Jeffrey R. Chen, and Stewart T. Wu. "Precision and fast wavelength tuning of a dynamically phase-locked widely-tunable laser." Optics express 20.13, 14234-14243, (2012).

[41] Drever, R.W.P., J.L. Hall, F.V. Kowalski, J. Hough, G.M. Ford, A.J. Munley, H. Ward, Appl. Phys. B, 31, 97105, (1983).

[42]Fix, Andreas, Renaud Matthey, Axel Amediek, Gerhard Ehret, Florian Gruet, Christoph Kiemle, Volker Klein, Gaetano Mileti, Joao Pereira do Carmo, and Mathieu Quatrevalet, "Investigations on frequency and energy references for a space-borne integrated path differential absorption lidar", Proceedings of the International Conference on Space Optics, vol. 10, (2014).

[43] Beck, Jeff, et al. "A highly sensitive multi-element HgCdTe e-APD detector for IPDA lidar applications." Journal of Electronic Materials 43.8, 2970-2977, (2014).

[44] Sun, Xiaoli, James B. Abshire, and Jeffrey D. Beck. "HgCdTe e-APD detector arrays with single photon sensitivity for space lidar applications." SPIE Sensing Technology+ Applications. International Society for Optics and Photonics, (2014).

[45] Sun, Xiaoli, James B. Abshire, Jeffrey D. Beck, Pradip Mitra, Kirk Reiff, and Guangning Yang. "HgCdTe avalanche photodiode detectors for airborne and spaceborne lidar at infrared wavelengths." Optics Express 25, 14, 16589-16602, (2017).

[46] Abshire, J.B., Ramanathan, A.; Riris, H.; Mao, J.; Allan, G.R.; Hasselbrack, W.E.; Weaver, C.J.; Browell, E.V. "Airborne Measurements of CO2 Column Concentration and Range Using a Pulsed Direct-Detection IPDA Lidar," Remote Sensing 2014, 6, 443-469, (2014)

[47] Riris, Haris, Kenji Numata, Stewart Wu, Brayler Gonzalez, Michael Rodriguez, Stan Scott, Stephan Kawa, and Jianping Mao. "Methane optical density measurements with an integrated path differential absorption lidar from an airborne platform." Journal of applied remote sensing 11, no. 3 (2017): 034001.

[48] Fix, Andreas. "Tunable light sources for lidar applications." Atmospheric Physics. Springer Berlin Heidelberg, 2012. 509-527.,

[49] Li, Steven, Haris Riris, Kenji Numata, Stewart Wu, Demetrios Poulios, Anand Ramanathan, James Abshire, and Michael Krainak. "Tunable narrow linewidth laser source for a methane lidar," Aerospace Conference, 2012 IEEE, pp. 1-8. IEEE, (2012).

[50] White, Kenneth O., and Stuart A. Schleusener. "Coincidence of Er: YAG laser emission with methane absorption at $1645.1 \mathrm{~nm}$." Applied Physics Letters 21.9, 419-420, (1972).

[51]Wang, X., et al. "Dual-wavelength Q-switched Er: YAG laser around $1.6 \mu \mathrm{m}$ for methane differential absorption lidar." Laser Physics Letters 10.11 (2013): 115804.

[52] Tang, Pinghua, et al. "Stable and wavelength-locked Q-switched narrow-linewidth Er: YAG laser at 1645 nm." Optics express 23.9, 11037-11042, (2015).

[53] Fritsche, H., O. Lux, X. Wang, Z. Zhao, and H. J. Eichler. "Resonantly diode pumped Er: YAG laser systems emitting at $1645 \mathrm{~nm}$ for methane detection." Laser Physics Letters 10, no. 10, 105805, (2013).

[54] Gao, Chunqing, Lingni Zhu, Ran Wang, Mingwei Gao, Yan Zheng, and Lei Wang. "6.1 W single frequency laser output at $1645 \mathrm{~nm}$ from a resonantly pumped Er: YAG nonplanar ring oscillator." Optics letters 37, no. 11, 1859-1861, (2012).

[55] Kudryashov, Igor, and Evgenii Kotelnikov. "Tunable Q-switched Solid State Laser for Methane Detection." SPIE LASE, pp. 100821I-100821I, International Society for Optics and Photonics, 2017.

[56] Mackenzie, Jacob, James Grant-Jacob, Stephen Beecher, Haris Riris, Anthony Yu, David Shepherd, and Robert Eason, "Er:YGG planar waveguides grown by pulsed laser deposition for LIDAR applications." SPIE LASE, 100820A-100820A, International Society for Optics and Photonics, 2017.

[57] Delahaye, T., S. E. Maxwell, Z. D. Reed, H. Lin, J. T. Hodges, K. Sung, V. M. Devi, T. Warneke, P. Spietz, and H. Tran, "Precise methane absorption measurements in the $1.64 \mu \mathrm{m}$ spectral region for the MERLIN mission." Journal of Geophysical Research: Atmospheres 121.12, 7360-7370, (2016). 